\title{
Collecting Artifact Data from Craftsmen with Participatory Design Methods
}

\author{
Fiona Yasmine ${ }^{1, *}$ Arianti Ayu Puspita ${ }^{2}$ Andar Bagus Sriwarno ${ }^{3}$ \\ ${ }^{1}$ Bandung Institute of Technology, Indonesia \\ ${ }^{2}$ Bandung Institute of Technology, Indonesia \\ ${ }^{3}$ Bandung Institute of Technology, Indonesia \\ *Corresponding author. Email: fionayasmine13@gmail.com
}

\begin{abstract}
The culture from artifacts in Indonesian society is a culture that has existed for a long time and has been passed down from generation to generation until now. Craftsmen are the one who produced the cultural artifact and has its own culture that still attached to them until now. Information related to cultural artifacts that are very diverse can be seen from the craftsmen's point of view and their interaction with the artifact. However nowadays information related to the production process of cultural artifacts and the link between craftsmen and cultural artifacts began to be difficult to find. Preservation of cultural artifacts and information related to craftsmen are important to increase their cultural value. Participatory design can be a method for collecting artifact data by involving craftsmen related to the cultural artifacts they produce. This research involves ceramics craftsmen in Cianjur who has a wide market across Indonesia, especially market from Papuan people who made these ceramic into artifacts that had high value for local culture in their society. This research is necessary for the need of data collecting of cultural artifacts and the connection with the ceramic craftsmen and the preservation of the craftsmen's culture using participatory design methods in producing cultural artifacts. This research aims to identify the application of participatory design methods of cultural artifact data collecting for the preservation of craftsmen culture with the production of cultural artifacts and turn the data outcome into a digital museum. Using a qualitative approach that refers to participatory design methods. The output from this research is an application of participatory design methods and design recommendations from collecting cultural data as preservation that expected to encourage the craftsmen to continue to preserve their culture.
\end{abstract}

Keywords: Craftsmen, Cultural Artifacts, Data Collecting, Participatory Design.

\section{INTRODUCTION}

Participatory design is a design process and strategy by taking an approach that involves the public to create some results together to overcome something in the design process. In the context of participatory design, the challenges that exist are very diverse differences in society. Businesses, public sector organizations, research institutions, and communities can have different views on participatory design [1]. The purpose of participatory design focuses on participant activities on their daily lives, which can provide opportunities for participants to have rights and know the information they need related to the design process, searching for methods so that the final result is more contextual with the needs that will be used by the next generation. This research on collecting data on artifacts and craftsmen culture using the participatory design method with 3 main principles in participatory design [2], which are:

1. Participation, the value of participation involving participants from the beginning to the end of the design process.

2. Practice, participants activities in their daily lives or activities that only exist for certain moments.

3. Design, the notion of design is not only the final result but also the whole process from the beginning until the results created can be used for those who involved. 
The theory related to craftsmen is the basis of the selection of case studies of cultural artifacts by craftsmen in this research, where craftsmen are intangible cultural heritage and are part of history, this is related to what is created by craftsmen, which is a production technique and the inherit the culture, and the artifacts produced by craftsmen are classified as culture brought by the craftsmen themselves [3]. So that the selection of this case study of the craftsmen's cultural artifacts can become a reflection that the artifacts produced are the result of the culture that exists in these local craftsmen [4].

The public who involved in collecting data for this research are ceramic craftsmen (Pancaniti Ceramics) located in Cianjur, West Java. This craftsmen is one of the local cultures of the Cianjur area have existed since 1970 and are now entering the 3rd generation which is currently owned by Teh Nuni. Pancaniti Ceramics has a culture of ceramic craftsmen since its open until now and still maintains its ceramic characteristics, which are ceramics with a thousand cracks (the result of ceramic finishing), celadon color, blue color, and manual painting with the specialty from Pancaniti Ceramics' craftsmen which is getting harder to find. Apart from the characteristics of its ceramics, Pancaniti Ceramics has a very wide market across Indonesia and a permanent market that has existed for a very long time until now with very large demand and is still running, It's Papuan people who have known these ceramics (called Chinese Ceramics) for hundreds of years because the arrival of Chinese traders who used ceramics as a medium for exchange [5]. Uniquely, the ceramics produced by Pancaniti purchased by the Papuan people are Chinese Ceramics and they make these Chinese Ceramics as cultural artifacts that have a very high value, are used for many traditional events, and become a high symbol in their society, for example as a medium of exchange, dowry, inheritance, and so on. From the culture of the Papuan people, Pancaniti Ceramics does not eliminate their ceramics production culture that has existed since its first generation because this culture is one of the iconic things from Cianjur, but over time Pancaniti Ceramics craftsmen begin to decrease and it is getting harder to find information about ceramic craftsmen and cultural artifacts characteristically. So, this research with the method of collecting data on artifacts and craftsmen culture based on participatory design is expected to be a new way that is more effective, especially for design study that can be applied to the development of craftsmen and their designs as well as archiving artifacts and culture with the final results for digital museums [6], and has benefits for many people, such as researcher and craftsmen who involved.

\section{CONTENTS}

The participatory design in this research is between the involvement of craftsmen to collect data on their culture and the data of ceramic artifacts produced by them, which have an attachment to the traditional market of the Papuan people with the output for artifact and cultural data for digital museums. It is also intended for cultural preservation with recommendations for the development of facilities for craftsmen from researcher.

\subsection{Methods}

The method used in this research is a qualitative approach [7]. The main method is the participatory design method, which is applied to this research on collecting data on artifacts and culture namely the MUST method [2]. This method is a participatory design method involving public participation which is oriented towards socio-cultural. The process of collecting data using is by interviewing the Pancaniti Ceramics craftsmen.

The participatory design MUST method has 4 parts (Figure 1), they are concepts, principles, project organization, also techniques and tools. The 4 parts of the MUST method are elaborated into this research based on the case study of craftsmen so that it is formed into the flow of the method in this research (Figure 2). Each part of the MUST method is used as a basic principle in the participatory design stages that are applied. The concepts section becomes the basis for communication in delivering the system to involve the public, the principles section becomes the basis for engaging the public so that it is involved and motivated in the process and generate preservation, cultural development, and publication which is also based on the project organization which is expected to become an offer to provide benefits for craftsmen, as well as techniques and tools become the basis for the process of collecting data with research limitations. The object to be studied is an artifact produced by Pancaniti Ceramic craftsmen. In the process of collecting data on ceramic artifacts, there are research parameters that are used in this research. The variables are visual artifacts (physical objects), information on material types, dimensions of artifacts, product knowledge, the function of artifacts, history/background of these artifacts. 


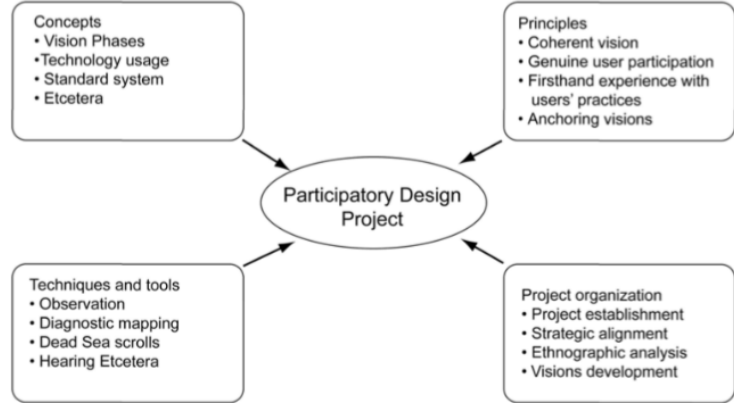

Figure 1 MUST method

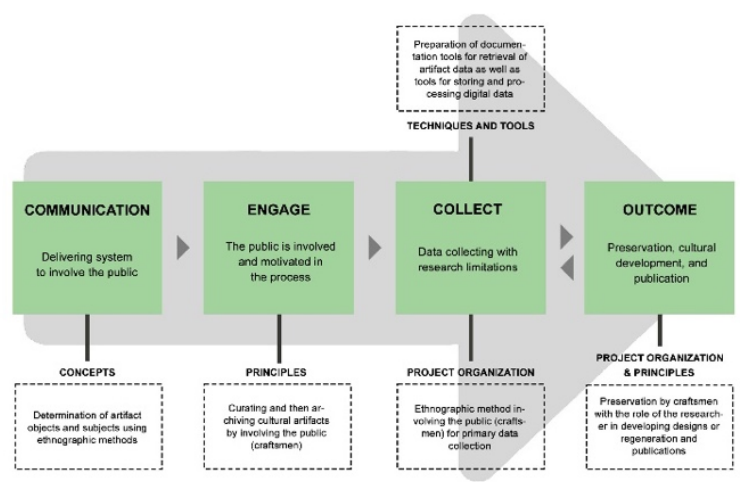

Figure 2 Application of MUST method in case study

\section{RESULTS}

\subsection{Results of Participatory Design Methods}

The results generated from the participatory design method were obtained from the Pancaniti Ceramics' craftsmen directly, with unstructured interviews were conducted and contained open-ended questions with the aim of obtaining points of view and opinions from the craftsmen. Some of the craftsmen involved in collecting data of cultural and artifacts produced by Pancaniti Ceramics, which are Teh Nuni (Owner and craftsmen of Pancaniti Ceramics) and one of the craftsmen is Mr. Ato. Based on the results of interviews with these craftsmen, here are the results related to culture and history:

- The process of passing down the cultural history from the first generation to the third generation related to this ceramic business, from the characteristics of the ceramic artifacts, tools for producing ceramics, craftsmen concepts, and the ability of craftsmen (production activities).

- Regular customer of Pancaniti Ceramics is Papuan people who make this ceramic artifact into a cultural artifact that has a very high value, because these artifacts keep on purchased for the traditional and cultural needs of the Papuan people.

- Pancaniti Ceramics still maintains its ceramic characteristics, which are thousand cracked ceramics (results of the finishing), celadon color, blue color, and manual painting motive.

- The involvement of these craftsmen in collecting data on their ceramic cultural artifacts is expected to encourage the owner's desire to record their ceramic artifacts, so that they can be preserved and passed on to future generations.

- Development of a design recommendation for the ceramics, ceramic artifact storage gallery into a home-scale display facility, and the supporting facilities.

Collecting data on artifacts through a participatory design process also has benefits for Pancaniti Ceramics, which are archiving ceramic artifacts produced, being able to introduce them to the society through sales, being able to tell and bring back their cultural history so that their characteristics are maintained, and craftsmen can be encouraged to participate in collecting data of ceramic artifacts. In addition to the data obtained, the production process and activities doing by the craftsmen in their daily lives are also documented, starting from the process of forming ceramics, drying, making manual painting motives, burning, and finishing.

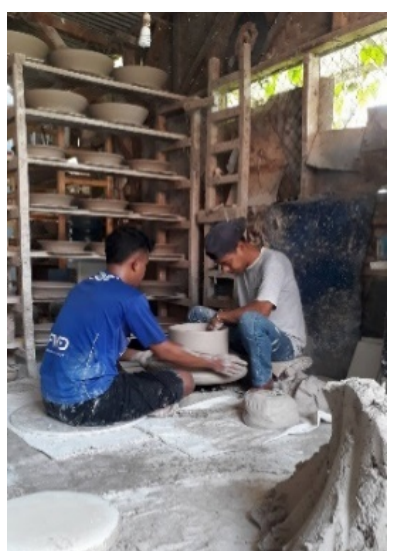

Figure 3 Ceramic forming process 


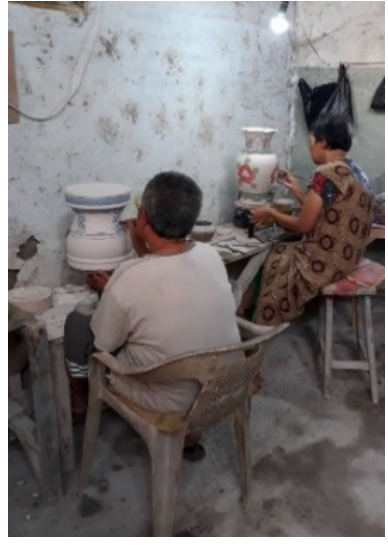

Figure 4 Manual painting process on ceramics

From the results of the data obtained in this research, the author found that there are several important things that can be categorized as findings in this Pancaniti Ceramics case study, which are:

1. There are many challenges in maintaining the distinctive design of Cianjur local craftsmen, because it will be passed down to the next generations (background, there is a historical / cultural value in Cianjur), without eliminating Pancaniti's market.

2. The owners of Pancaniti Ceramics have started to try new and more modern designs through internet references, this is a factor in the development of socio-cultural issues in the society, but the owners of Pancaniti Ceramics also maintain the main characteristics of cultural artifacts produced by Pancaniti Ceramics because they keeping the culture of the Papuan people.

3. Owners of Pancaniti Ceramics also expand their market by using social media to publish cultural artifacts produced by Pancaniti Ceramics, thereby opening new market opportunities by making people more familiar with cultural artifacts of Pancaniti Ceramics typical of Cianjur, especially young people because of its higher accessibility to social media.

\subsection{Results from data collecting of Pancaniti Ceramics artifacts with participatory design method}

The collection of cultural artifacts distinctive of Pancaniti Ceramics is ceramics which is divided into 2 types of ceramics, that are mold ceramics and swivel ceramics. The results of data collection based on the research parameters, both the cultural artifacts produced and the tools used in the production at the Pancaniti Ceramics.

Table 1. Research Parameter Variables

\begin{tabular}{|l|l|}
\hline \multicolumn{1}{|l|}{$\begin{array}{l}\text { Research } \\
\text { Variables }\end{array}$} & Description \\
\hline Name & Celadon Chinese ceramic plate artifact with dragon motive \\
\hline Artifact description & $\begin{array}{l}\text { This plate-shaped ceramic with a dragon motive has a texture that } \\
\text { emerges by forming the scales of a dragon's body, made of porcelain } \\
\end{array}$ \\
& $\begin{array}{l}\text { ceramics using swivel and embossed painting techniques. This plate } \\
\text { ceramic artifact is one of the icons from Pancaniti Ceramics so that it } \\
\text { continues to be produced with its distinctive celadon color }\end{array}$ \\
\hline Material type & Porcelain ceramics \\
\hline Dimensions & $300 \times 300 \times 55$ mm \\
\hline Technique & Swivel techniques \\
\hline Function & Decoration, traditional cultural artifact, medium of exchange, dowry \\
\hline History / artifact background & This artifact has a high value in the culture of the Papuan people and is \\
& used as a very expensive cultural artifact \\
\hline
\end{tabular}




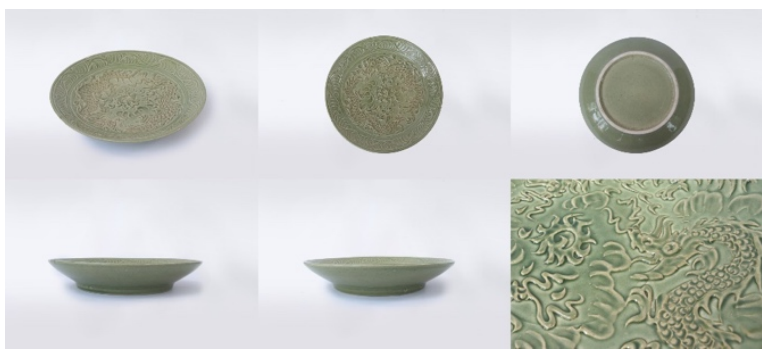

Figure 5 example of full documentation of one ceramic artifact from data collection (Chinese dragon ceramic plate artifact)

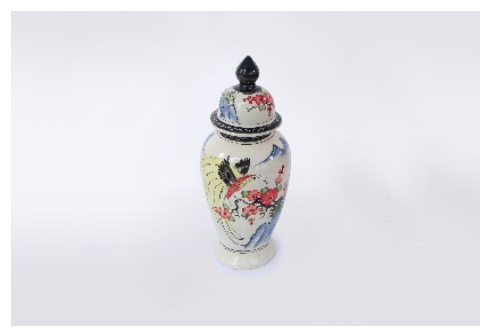

Figure 6 Bird of paradise motive ceramic jar

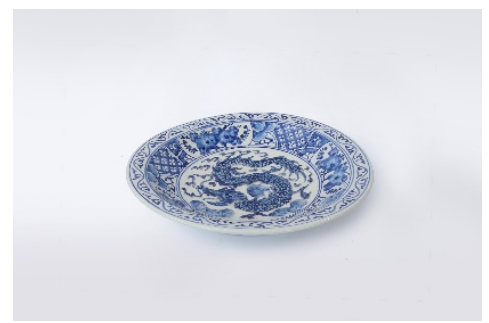

Figure 7 Chinese blue dragon ceramic plate

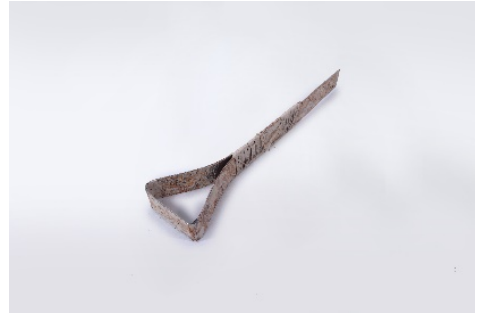

Figure 8 Ceramic production tools (butsir/sudip)

From more than 20 documented cultural artifacts, it was found that each artifact has a value that is not much different from one another, but the difference lies in the function of the artifact when it is on the market, the value formed by the community when it is purchased and used, for example ceramic jars and ceramic plates that are used as decorations, or collections by someone who makes it a high value for their personally, but it is different from the Papuan market which makes ceramic jars and plates artifacts as cultural traditional artifacts where the more ceramic artifacts they have the better considered highly by their society, so that ceramics are a sacred artifact for certain people. Apart from the ceramic artifacts themselves, the production tools used by the Pancaniti Ceramics craftsmen also have a high cultural value because these production tools have become typical production tools that only used by these craftsmen, so the value is a culture in production techniques.

It was found that the parameters of the object research are the main points in the process of analyzing artifacts in this research, because these parameters are important elements of artifacts in the collection for digital museums, and each of these parameters is connected with one another. The results

Table 2. Analysis Results of the Cultural Artifacts of Pancaniti Ceramics Based on the Research Parameters

\begin{tabular}{|c|c|}
\hline Research parameter variables & Description \\
\hline Visual & $\begin{array}{l}\text { The results of the documentation from all of the side artifacts turns } \\
\text { out very good and detailed }\end{array}$ \\
\hline Material type & Porcelain ceramics \\
\hline Dimensions & $\begin{array}{l}\text { The result is precise (from } 100 \times 100 \times 70 \mathrm{~mm} \text { to } 500 \times 500 \times 600 \\
\mathrm{~mm} \text { and above) }\end{array}$ \\
\hline Product knowledge & $\begin{array}{l}\text { Artifact description describing the artifact, its features, texture, } \\
\text { production technique, and meaning or symbol (if any) }\end{array}$ \\
\hline Function & $\begin{array}{l}\text { The function of the artifact according to the type of artifact, mostly } \\
\text { for decoration }\end{array}$ \\
\hline History / artifact background & $\begin{array}{l}\text { The background of each artifact is mostly ceramics from the } \\
\text { Papuan market culture, but there are also modern market demands }\end{array}$ \\
\hline
\end{tabular}


of the analysis of cultural artifacts of Pancaniti Ceramics based on the research parameters are as follows: (Table 2)

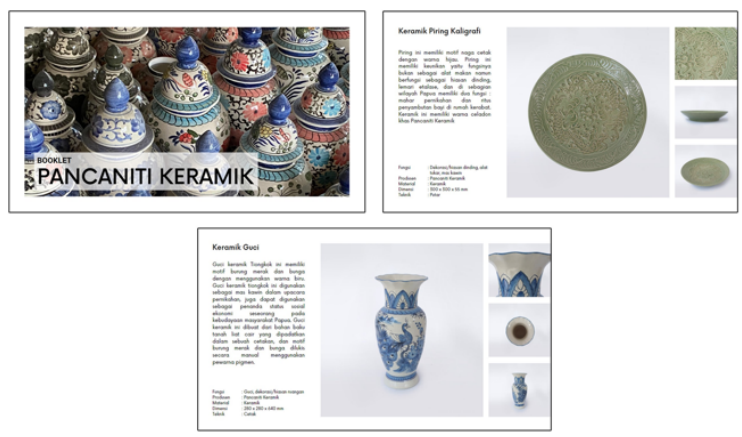

Figure 9 Design visualization of Pancaniti Ceramics' booklet

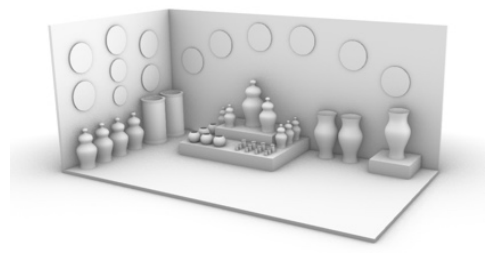

Figure 10 Design visualization of Pancaniti Ceramics' main gallery display

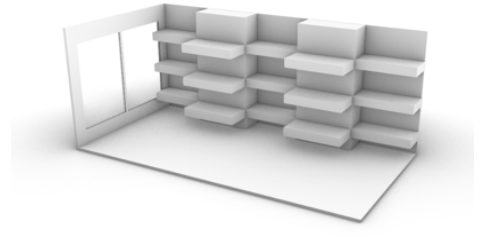

Figure 11 Design visualization of Pancaniti Ceramics' storage display

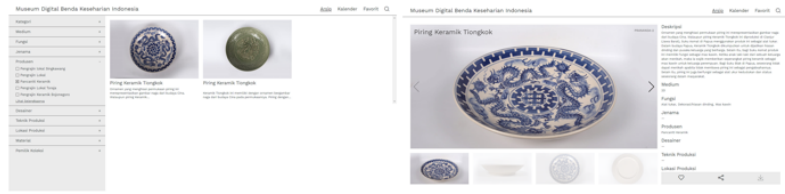

Figure 12 Visualization of Pancaniti Ceramics' artifact data collection on the digital museum page

\subsection{Recommendations from participatory design method for Pancaniti Ceramics}

From the results of participatory design data that have been obtained, it can be used as a reference in providing design recommendations from researcher to craftsmen in the form of design visualization of Pancaniti Ceramics' booklet (Figure 5), design visualization of the Pancaniti Ceramics display facilities (Figure 6), visualization on digital museum pages (Figure 7). Beside the design recommendations, the researcher also provides the development of Pancaniti ceramic designs from the results of participatory designs. By maintaining its characteristics, which is the shape of ceramics can be simplified, maintain its manual painting technique with modern motives, coloring characteristics can be developed by color mixing techniques, and still maintain the characteristic of the thousand cracks by finishing with a matte coating.

\section{DISCUSSION}

From the main analysis of Pancaniti Ceramics obtained from the MUST method, the goals that can be achieved between researcher and craftsmen are data collection on the design process of craftsmen and the ceramics they produce and increase cultural awareness of Pancaniti Ceramics by preserving and collecting data on cultural artifacts. The participatory design method can increase the sales of Pancaniti Ceramics from the involvement of researcher in developing existing design facilities, and can increase the economic value of the craftsmen. This method can also foster a familial factor in the Pancaniti Ceramics in the process of cultural regeneration for the next generation. In its application, the MUST method can be applied to case studies of craftsmen but needs to be further elaborated on the principles that are tied to the MUST method section, because in the application of Pancaniti Ceramics there needs to be a principle to find out the source of Pancaniti Ceramics's attachment to the market culture of the Papuan people. The part of the MUST method that has the most significant impact on participatory design in this study is the project organization, because the results of this stage are collecting process and producing an outcome. From these results, it was found that the ability of the craftsmen of Pancaniti Ceramics is an ability that has been existed since Pancaniti Ceramics was founded and is still maintained until now. The existing process design from the beginning until now is still the same, where the existing ceramic designs originated from the many markets demands of the Papuan people to buy Chinese ceramics as artifacts for traditional cultural purposes, so that the Chinese ceramic designs in the Pancaniti Ceramics follow the many markets demands of the Papuan people.

In the process of data collection, there are factors or biases that affect the process. These factors are divided into two types, external factors and internal factors. 


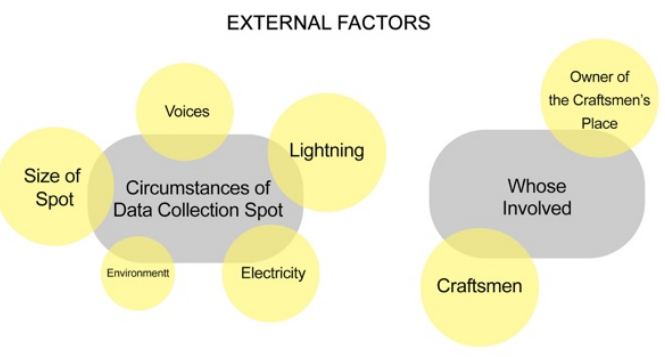

Figure 13 External factors affecting the data collection process.

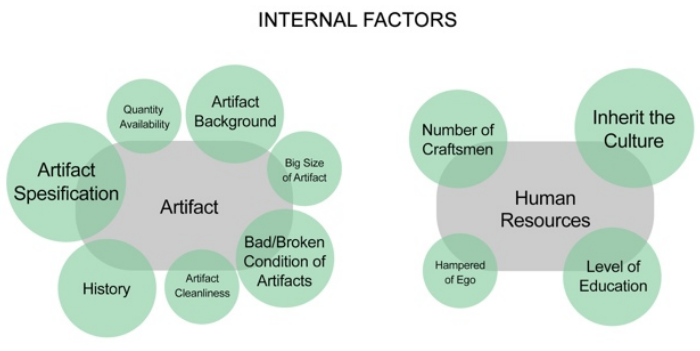

Figure 14 Internal factors affecting the data collection process.

These external and internal factors become the main focus in research on methods of collecting data on cultural artifacts of craftsmen based on participatory design. The external and internal factors can also become a factor that affect the process of passing down the cultural history to the next generation. Besides that, there are also cultural changes in the Pancaniti Ceramics. Pancaniti Ceramics' current condition is keeping up with the nowadays situation at the market which is more modern. In the data collection process, several things were found that affects the changing culture of the craftsmen. The following are things that affect the shifting in cultural values at the Pancaniti Ceramics:

1. Trend shifting

2. Development of modern market

3. The fading of local craftsmen' culture, because it is considered as conventional

4. The next generation lacks the motivation to maintain the culture of the previous generation (because the information obtained is minimal)

The design recommendations given to the Pancaniti Ceramics' craftsmen are the visualization of the Pancaniti Ceramics' booklet design, the design of the display facilities for the main Pancaniti Ceramics' gallery, the design of the Pancaniti Ceramics' storage display facilities, the visualization of data collection of Pancaniti Ceramics' artifacts on the digital museum page, and design development of Pancaniti ceramic. The process after providing the five designs is discussion, negotiation, and explanation regarding the design to the owner of Pancaniti Ceramics in order to find out the opinions, comments, and input from the owner. The design recommendations are expected to be useful for craftsmen in the development of Pancaniti Ceramics, where these design recommendations are the result of a participatory design process with craftsmen.

The results of the booklet design recommendations, visualization of the Pancaniti Ceramics artifact collection on the digital museum page, and the design development received a positive response, it could really help Pancaniti Ceramics in its ceramic artifact archiving and developing design activities. It's good, clear, and understandable for readers because there is ceramic documentation with several looks, there are descriptions, artifact details, and so on. In the booklet, there are also some of the explanations about Pancaniti Ceramics' market that is the Papuan people, so that the owner of Pancaniti Ceramics hopes that the booklet can also provide information to other buyers that the artifact produced by Pancaniti Ceramics is an artifact that has a high value of culture for the Papuan people. And for the design recommendations for Pancaniti Ceramics' display facilities, the main gallery is possible, but for the design storage will be affected by a large and erratic number of ceramics. But with the two recommendations for the design of the display facility, it is hoped that it can be a recommendation for the development of the Pancaniti Ceramics. Other than that, the application of the participatory design method in this research can generate several things that later can be used in developing this method, especially for case studies of craftsmen, which are negotiation, medium of communication, collecting \& design development, preservation, and publication. So, these five points can be called the result of the application of participatory design methods on craftsmen from this research.

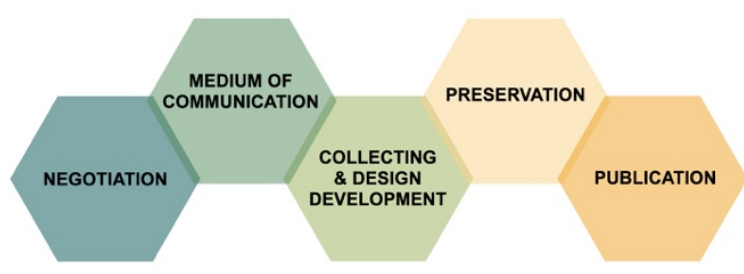

Figure 15 Result of the participatory design methods on craftsmen. 


\section{CONCLUSION}

This participatory design method in collecting craftsmen artifact data not only documented the artifacts, but also activities, cultural/historical settings, and the actual situation. Based on a case study for collecting data related to cultural artifacts of Pancaniti Ceramics craftsmen, it was found that the public's point of view has an important role because it can provide information related to the background of the story that is only known by certain people or the owner of the cultural artifacts. There are several factors that affect the process of passing down the cultural history to the next generation and its artifacts, as well as a culture that affects the surrounding society. Through interviews, the researcher was able to find several problems, that the culture owned by Pancaniti Ceramics will still be maintained as long as the market of Papuan people is still preserving their local culture, and the culture of Pancaniti Ceramics is affected by various social factors both internally and external.

To collecting data on artifacts, the participatory design method is used by the researcher to provide benefits for craftsmen with design recommendations for the development of the Pancaniti Ceramics facility, so that craftsmen can directly experience the benefits of participatory design methods and are aware of preserving their culture, and for the researcher can get the benefit from the results of this method as literacy in the field of design and development through digital museums. So, the application of the participatory design method as an output of the research has fulfilled its objectives, where the participatory design method can be an alternative method in collecting cultural data and artifacts on local craftsmen as a form of preservation.

\section{ACKNOWLEDGMENTS}

This article entitled Collecting Artifact Data from Craftsmen with Participatory Design Methods is one of the results of the research scope from the Master of Design Study conducted by the author at Bandung Institute of Technology and part of the P2MI ITB 2021 research.

\section{REFERENCES}

[1] M. Cozza, A. Cusinato, A.P. Mihalopoulos, Atmosphere in Participatory Design, Science as Culture, 2019

DOI: https://doi.org/10.1080/09505431.2019.1681952
[2] J. Simonsen, T. Robertson, Routledge International Handbook of Participatory Design, Routledge, New York, 2013. DOI: https://doi.org/10.4324/9780203108543

[3] R. Sandgruber, H. Bichler-Ripfel, M. Walcher, Traditional Craftsmenship as Intangible Cultural Heritage and an Economic Factor in Austria, The Austrian Federal Chancellery, Vienna, 2019.

[4] Direct Create Community, Craft and Culture, 2016. [cited 2021 Mar 9]. Available from: https://medium.com/direct-create/craft-andculture-241f069f79e3.

[5] L. Suroso, Ceramics Tiongkok, Alat Tukar yang Membudaya di Papuan, 2018 [cited 2021 July 5]. Available from: https://suarapapuan.com/2018/12/02/ceramicstiongkok-alat-tukar-yang-membudaya-dipapuan/.

[6] Y.C. Li, A.W.C. Liew, W.P. Su, The Digital Museum: Challenges and Solution, Australia, 2019.

[7] J.W. Creswell, Research Design: Qualitative, Quantitative, and Mixed Methods Approaches, Third Edition, SAGE Publications Inc., London, 2009. 